\title{
EDITORIAL
}

\section{Multi-drug-resistant tuberculosis (MDR-TB): Current situation in South Africa}

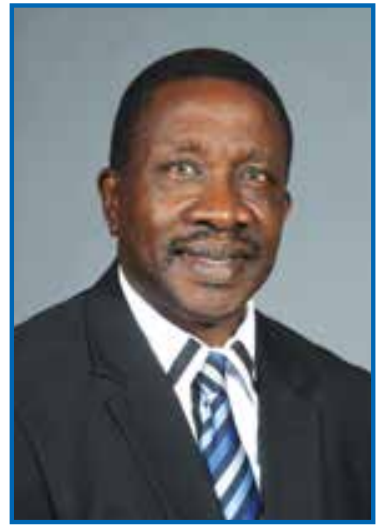

Multi-drug-resistant tuberculosis (MDR-TB) is a form of tuberculosis (TB) infection which is resistant to treatment with at least two of the most powerful first-line anti-TB drugs, namely isoniazid and rifampicin. Globally, MDR-TB caused an estimated 480000 new TB cases and 250000 deaths in 2015 and accounted for $3.3 \%$ of all new TB cases worldwide. ${ }^{1}$ MDR-TB, or rifampicin-resistant TB, causes $3.9 \%$ of new TB cases and $21 \%$ of previously treated TB cases, and most MDR-TB cases occur in South America, southern Africa, India, China, and the former Soviet Union.

A South African Health Systems Trust report indicated that despite a global slowing down in new TB cases since 2003, South Africa recorded the world's second-highest rate of new cases in 2006 after Swaziland. More people died of TB in South Africa that year than in any other country in the world. Zimbabwe and Mozambique had the next highest TB death rates. The global TB cure rate for 2005 was $78 \%$, but South Africa's cure rate was only $58 \%$, which was the third worst in the world. ${ }^{2}$

The WHO 2016 global report on country profiles for the 30 high-burden countries for tuberculosis paints a very sobering picture for South Africa. In 2015, with the estimated population of 54 million, the incidence rate for TB (including HIV+TB) was 834 cases per 100000 . Furthermore, the incidence rate for MDRTB was 37 cases per 100000 and the TB treatment coverage (notified/estimated incidence) was 63\%. In 2015, the South African national TB budget was US\$425 million. ${ }^{3}$ The latter should have produced better TB control outcomes as countries with less financial resources performed better. For example, in 2015, Kenya, with a population of 46 million, recorded the TB incidence rate (including HIV+TB) of 233 cases per 100000 population, MDR-TB incidence rate of 4.3 cases per 100000 population, and TB treatment coverage (notified/estimated incidence) of $76 \%$ with a national TB budget of US\$59 million. ${ }^{3}$
We are aware that MDR-TB is man-made due to the following factors:

a. Poor patient adherence to complete the full course of TB treatment

b. Healthcare providers prescribing the wrong treatment, wrong dose, or length of time for TB drugs

c. Inadequate monitoring of patients while on their anti-TB drugs (DOTS)

d. Irregular anti-TB drug supply at health facilities

Obviously to reduce the incidence of MDR-TB, it is imperative that TB is treated correctly the first time. It is these man-made factors that result in the emergence of MDR-TB. Healthcare providers need to be better trained at our various nursing colleges and medical schools on how to manage TB, with regular and intense follow-up in-service training sessions. In addition, patients need more motivation and education to appreciate the importance of adherence to the six-month TB treatment programme. Issues of patient monitoring, while taking their drugs, can be addressed by employing more community health workers to supervise and motivate patients. The problem with irregular drug supplies can be addressed by proper drug stock planning and regular payment of drug suppliers by provincial health departments. In South Africa, the human and financial resources are available for the successful implementation of the national TB control programme to ultimately reduce the incidence of MDR-TB. However, a well-coordinated implementation strategy between the national and provincial health departments is lacking. That is the crux of the matter that is causing the country's lower than expected TB control outcomes.

\section{Prof. Gboyega A Ogunbanjo}

Editor-in-chief: SAFPJ

\section{References}

1. World Health Organization. "Diagnosis and notification of multidrug-resistant TB" (PDF). WHO MDR TB Factsheet (2016 Update). http://www.who.int/tb/challenges/ $\mathrm{mdr} / \mathrm{mdr}$ _tb_factsheet.pdf [accessed 29 April 2017]

2. Kerry Cullinan. South Africa has worst TB prevalence in the world - report. Health Systems Trust 2017 report. http://www.hst.org.za/news/south-africa-has-worsttb-prevalence-world-report [accessed 29 April 2017]

3. World Health Organization. WHO 2016 global report on country profiles for the 30-high burden countries for tuberculosis http://www.who.int/tb/publications/ global_report/gtbr2016_annex2.pdf?ua=1 [accessed 29 April 2017] 